Tropical Journal of Pharmaceutical Research June 2012; 11 (3): 455-459

(C) Pharmacotherapy Group, Faculty of Pharmacy, University of Benin

Benin City, 300001 Nigeria.

All rights reserved.

Available online at http://www.tjpr.org http://dx.doi.org/10.4314/tjpr.v11i3.15

\title{
Bisphenol A Detection in Various Brands of Drinking Bottled Water in Riyadh, Saudi Arabia Using Gas Chromatography/Mass Spectrometer
}

\author{
Mai A Elobeid ${ }^{1 *}$, Zainab M Almarhoon ${ }^{2}$, Promy Virk ${ }^{1}$, Zeinab K Hassan ${ }^{1}$, \\ Sawsan A Omer ${ }^{1}$, Maha EIAmin ${ }^{1}$, Maha H Daghestani ${ }^{1}$ and Ebtisam M \\ AlOlayan ${ }^{1}$ \\ ${ }^{1}$ Department of Zoology, ${ }^{2}$ Department of Chemistry, Faculty of Science, King Saud University, Women's Students- \\ Medical Studies \& Sciences Section, Riyadh, Saudi Arabia
}

\begin{abstract}
Purpose: To assess whether bisphenol A contamination occurred in seven brands of bottled drinking water in Riyadh, Saudi Arabia.

Methods: Liquid-liquid extraction (using dichloromethane) was used to analytically extract bisphenol A from drinking water bottles and a gas chromatograph-mass spectrometer was employed for its detection using a splitless capillary column and helium as the carrier gas.

Results: The concentration of bisphenol A (BPA) was high in all the bottled water brands tested. The mean concentration of BPA of the bottled water stored indoors (4.03 $\mathrm{ng} / \mathrm{L})$ was significantly lower than that stored outdoors (7.5 $\mathrm{ng} / \mathrm{L})$.

Conclusion: Our results show that significant amounts of BPA leached from bottle containers into the water. Long storage of bottled water under direct sunlight should be avoided to reduce the risk of human exposure to BPA.
\end{abstract}

Keywords: Bisphenol A, Bottled water, Public health, Endocrine disruptors, Saudi Arabia 


\section{INTRODUCTION}

Bisphenol A (BPA) has been well characterized as an endocrine disruptor which can mimic the body's own hormones $[1,2]$, potentially leading to reproductive defects, cancer, obesity and diabetes [2,3]. BPA is a key monomer and plasticizer in the production of epoxy resins and polycarbonate plastic. Epoxy resins are used to coat the interior of food cans, storage vats, water containers, infant bottles, and other consumer products and water pipes.

Human safety levels for BPA are currently under review as a result of new scientific studies [4,5]. A 2011 study that investigated the number of chemicals to which pregnant women in the U.S. are exposed found BPA in $96 \%$ of the studied women [6]. Furthermore, drinking water and other beverages from plastic bottles made with BPA increased the urinary levels of the toxic chemical by nearly $70 \%$ [7]. Many questions had been raised about the possibility of BPA migrating from the bottles under poor conditions such as high temperature and sun radiation.

General population exposure (99\%) is by eating food or drinking beverages that contain trace amounts of BPA. In general, plastics that are marked with recycle codes 1 , $2,4,5$, and 6 are very unlikely to contain BPA. Some, but not all, plastics that are marked with recycle codes 3 or 7 may be made with BPA. Type 7 is the catch-all "other" class, and some type 7 plastics, such as polycarbonate (sometimes identified with the letters "PC" near the recycling symbol) and epoxy resins, are made from BPA monomer $[8,9]$.

Bottled water consumption is important in Saudi Arabia, being the main source of drinking water. The aim of the present study was to investigate the presence of BPA in seven brands of bottled drinking water under different storage situations in the province of Riyadh, Saudi Arabia.

\section{EXPERIMENTAL Materials}

Bisphenol A, and bisphenol A (BPA- $\left.d_{16}\right)$ were purchased from Loba Chemie Labrotary (Mumbai, India). Dichloromethane was obtained from King Saud University, Riyadh, Saudi Arabia. Bisphenol A $\left(B P A-d_{16}\right)$ was used as an internal standard. Bottled water samples were purchased from local stores in Riyadh, Saudi Arabia.

\section{Sample preparation}

Seven brands (labeled 1 - 7) of commonly consumed bottled water were randomly purchased from local supermarkets in Riyadh, Saudi Arabia. A set of seven different brands of bottled water was purchased from among those stored in indoors while the second set (the same brands as those in the first set) was set was purchased from among those stored outdoors. In each case, water in the bottles was immediately extracted and analyzed. Seven water bottles per brand were used in the analysis. The first set of bottles was stored for a couple of days at room temperature prior to extraction. A sample of water $(1 \mathrm{~L})$ was transferred from each bottle to a separating glass funnel. Liquid-liquid extraction with dichloromethane $(3 \times 50 \mathrm{ml})$ was employed for the isolation of BPA. The extract was concentrated under a gentle stream of nitrogen.

\section{Determination of bisphenol A}

Gas chromatography/mass spectrometric (GC-MS) analysis of the BPA from water samples was carried out using a Perkin Elmer (Clarus 500) gas chromatography/ mass spectrometer. Separation was done using a capillary column Elite-5-MS (30 m x $0.25 \mathrm{~nm}, 0.5 \mu \mathrm{m}$ film thickness). Helium was used as the carrier gas with a constant flow rate of $0.1 \mathrm{ml} / \mathrm{min}$. The temperature of both ion source and quadropole was set at $150{ }^{\circ} \mathrm{C}$. A sample volume of $1 \mu \mathrm{L}$ was injected in splitless mode at an inlet temperature of 300 ${ }^{\circ} \mathrm{C}$. The GC oven temperature was set at 100 
${ }^{\circ} \mathrm{C}$ (for $2 \mathrm{~min}$ ) and then at $300{ }^{\circ} \mathrm{C}$ subsequently. The MS interface temperature was at $310^{\circ} \mathrm{C}$.

The linearity of the method was tested with a calibration standard curve at seven different concentrations within the range of $0.2-1.0$ $\mathrm{ng} / \mathrm{L}$. By using the internal standard, calibration was done by linear least square regression with concentration ranging from 0.2 to $1.0 \mathrm{ng} / \mathrm{L}$ for each of the BPA concentrations. Using the GC-MS data calibration handling method, the peak areas of each standard and their respective internal standards were calculated for each concentration. The percent relative standard deviation (RSD \%) was taken as the measure of precision of the method. It was calculated by dividing the standard deviation of the seven check standards by their theoretical mean concentration and then multiplied by 100. All the glassware were carefully washed with dichloromethane and left in a furnace at $500{ }^{\circ} \mathrm{C}$ for $2 \mathrm{~h}$. Glassware and solvents were carefully handled to avoid contamination. Reagent procedural blanks were regularly analyzed and all data presented in the study were collected for blank values.

\section{Statistical analysis}

The Prism 5 software was used in a one-way ANOVA analysis for statistical treatment of the results. A $p \leq 0.05$ was set as statistical significance.

\section{RESULTS}

Table 1 shows the physical characteristics of the examined bottled water brands. A linear fit of the ratios of the BPA over the internal standard peak areas was obtained with correlation coefficients $\left(R^{2}\right) \geq 0.99$. Recovery was in the range of $79-94 \%$. The detection limit for BPA was calculated from the standard deviation of seven replicates.

Bisphenol A identification was based on the relative abundance (i.e., based on a comparison between abundance of isotopes), while quantification was carried out using the relative response factor to the surrogate internal standard, BPA- $d_{16}$. Table 1 shows that the mean concentration of BPA in the seven bottled water was $4.03 \mathrm{ng} / \mathrm{L}$ for those stored at $25^{\circ} \mathrm{C}$ and $7.5 \mathrm{ng} / \mathrm{L}$ for those stored at $40^{\circ} \mathrm{C}$. The concentration of BPA in bottled water stored outdoors $\left(40{ }^{\circ} \mathrm{C}\right)$ was significantly higher $(p \leq 0.05)$ than in those stored indoors $\left(25^{\circ} \mathrm{C}\right)$. Among the water brands stored indoors, the difference between their BPA concentrations was not significant, e.g., 1 vs 5,1 vs 7,2 vs 3,2 vs 4 , 3 vs 4 , and 5 vs 6 . The same observation applies to those stored at the outdoors.

Table 1: Characteristics of the examined water bottles

\begin{tabular}{|c|c|c|c|c|c|c|c|}
\hline \multirow[t]{2}{*}{ Characteristics } & \multicolumn{7}{|c|}{ Bottled water brand code } \\
\hline & 1 & 2 & 3 & 4 & 5 & 6 & 7 \\
\hline \multicolumn{8}{|l|}{ Bottle } \\
\hline Color & Clear & Clear & Clear & LB & Clear & LB & Clear \\
\hline Resin identification code & 8 & 7 & 2 & 2 & $\mathrm{~N} / \mathrm{A}$ & $\mathrm{N} / \mathrm{A}$ & 12 \\
\hline \multicolumn{8}{|l|}{ Water } \\
\hline$p H$ & 7.5 & 7.1 & 7.6 & 7.2 & 7.5 & 7.4 & 8 \\
\hline $\begin{array}{l}\text { Indoor storage }\left(25^{\circ} \mathrm{C}\right) \\
\pm \mathrm{SD} \\
\text { Outdoor storage }\left(40^{\circ} \mathrm{C}\right) \\
\pm \mathrm{SD}\end{array}$ & $\begin{array}{l}4.23 \\
\pm 0.05 \\
7.90 \\
\pm 0.36\end{array}$ & $\begin{array}{l}3.53 \\
\pm 0.30 \\
8.60 \\
\pm 0.25\end{array}$ & $\begin{array}{l}3.23 \\
\pm 015 \\
6.30 \\
\pm 0.15\end{array}$ & $\begin{array}{l}3.13 \\
\pm 0.05 \\
6.20 \\
\pm 0.20\end{array}$ & $\begin{array}{l}4.83 \\
\pm 0.25 \\
7.20 \\
\pm 0.25\end{array}$ & $\begin{array}{l}5.13 \\
\pm 0.05 \\
7.40 \\
\pm 0.32\end{array}$ & $\begin{array}{l}4.16 \\
\pm 0.05 \\
8.80 \\
\pm 0.10\end{array}$ \\
\hline
\end{tabular}

Key: N/A = not available; $L B=$ light blue; all bottles were made of polyethylene tetraphathalate (PET); bottle volume = 1 $L$ 


\section{DISCUSSION}

Bisphenol $A$ is a chemical building block used primarily to make epoxy resins and polycarbonate plastic. Toyo'oka and Oshige found the concentration of BPA in drinking water bottles made from PET to be between 3 and10 ng/L [10], while another study did not detect BPA in different plastic containers for beverages, including drinking water [11]. Our results are in agreement with other studies which reported the presence of plasticizer residues in water stored in bottles $[10,12]$. This could be attributed to the migration of plasticizers from the bottle material to the water since bottle quality may vary depending on the raw material and the technology used in bottle production [12]. Cross contamination during analytical procedure due to wide use of plasticizer may be another cause.

Although it is recommended to store water bottles in a cool place and away from the sun and outdoors, in practice this is not always the case. Various processes are involved in water contamination by BPA, such as leaching from the container due to photolytic formation or degradation of organic compounds that could take place during the storage of bottled water [12]. BPA concentration released from bottles increases with storage time and under elevated temperature [12]. It had been reported that during the photolysis of BPA in deionized water under natural sun radiation, the concentration of BPA remained at $80 \%$ of the initial concentration during the first 5 days of exposure followed by a progressive decrease [13]. However, another study reported that BPA presents slow direct photolysis in neutral pure water under simulated solar irradiation, but the process is rapid in the presence of humic substances [13]. Another study determined endocrine disrupting chemicals (EDCs) such as BPA in water samples from PET and polyethylene (PE) bottles after outdoor exposure for 10 weeks at temperatures up to $30{ }^{\circ} \mathrm{C}[14]$; the present study, however, did not analyze samples over different periods of time.
Food packaging could be a source of xenobiotics, especially those with endocrine disrupting properties. Chemical leaching from food packaging into food contribute to human EDCs exposure and might lead to chronic disease in the light of current knowledge in this field. Even at low concentrations, chronic exposure to EDCs is toxicologically relevant. Concern increases when humans are exposed to combination of EDCs and/or during embryonic development and growth age.

Exposure to endocrine disruptors can occur through direct contact with chemicals or through ingestion of contaminated water and food, or air. Bisphenol A is listed as a possible priority substance subject to review for identification in the field of water policy. The ester bonds in BPA-based polymers are subject to hydrolysis and, therefore, BPA leaches into food and drinks from their storage containers. Heat and/or acids speed up the leaching process, and repeated washing of polycarbonate products have all been shown to result in an increase in the rate of leaching of BPA [2].

\section{CONCLUSION}

Bottled drinking water is an important avenue for human exposure to BPA. However, it is not clear whether the BPA detected in this study originated from the bottle or the water itself, or both. This will be a subject of a future study. Exposure to BPA poses risk to human health. Further research is required to study the broader effects and ingestion routes including food and water to make more realistic human health assessment of daily intake of BPA.

\section{ACKNOWLEDGEMENT}

The authors extend their appreciation to the Deanship of Scientific Research at King Saud University for funding the work through research group project no. RGP-VPP-033. 


\section{REFERENCES}

1. Elobeid $M$, Allison D. Putative endocrine disruptors and obesity: A Review. Curr Opin Endocrinol Diabetes Obes 2008; 15(5): 403-408.

2. Vom-Saal FS, Myers JP. Bisphenol A and risk of metabolic disorders. JAMA 2008; 300(11): 1353-1355.

3. O'Connor JC, Chapin RE. Critical evaluation of observed adverse effects of endocrine active substances on reproduction and development, the immune system, and the nervous system. Pure Appl. Chem 2003; 75 (11): 2099-2123.

4. Ginsberg G, Rice DC. Does rapid metabolism ensures negligible risk from bisphenol A? Environ. Health Perspect 2009; 117(11): 1639-1643.

5. Beronius $A$, Rudén $C$, Håkansson $H$, Hanberg A. Risk to all or none? - A comparative analysis of controversies in the health risk assessment of bisphenol A. Reprod Toxicol 2009; 29(2) 132146.

6. Woodruff TJ, Zota AR, Schwartz JM. Environmental chemicals in pregnant women in the United States: NHANES 2003-2004. Environ Health Perspect 2011; 119(6): 878-885.

7. Braun A, Kalkbrenner AE, Calafat MA, Bernert JT, Ye $X$, Silva $M J$, Barr $D B$, Sathyanarayana $S$, Lanphear $P B$. Variability and predictors of urinary bisphenol $A$ concentrations during pregnancy. Environ Health Perspect 2011; 119(1): 131-137..

8. Biello D. Plastic (not) fantastic: Food containers leach a potentially harmful chemical. Scientific American 2008; 2.
9. Fiege $H$, Voges HW, Hamamoto $T T$, Umemura $S$, Iwata T, Miki H, FujitaY, Buysch H J, Garbe D, Wilfried P. Phenol Derivatives. Ullmann's Encyclopedia of Industrial Chemistry. Weinheim: Wiley-VCH; 2002.

10. Tokunaga $\mathrm{OH}$, Liu X, Takay, Matsushima A, Shimohigashi $Y$. Direct evidence revealing structural elements essential for the high binding ability of bisphenol $A$ to human estrogen-related receptor-gamma. Environ Health Perspect 2008; 116(1): 32-38.

11. Shao H, Han J, Hu J, Wu G, Xue Y, Ma Y, Zhan S. Determination of alkylphenol and bisphenol $A$ in beverages using liquid chromatography/ electrospray ionization tandem mass spectrometry. Anal Chim Acta 2005; 530: 245252.

12. Amiridou $D$, Voutsa $D$. Alkylphenols and phthalates in bottled waters. Journal of Hazardous Materials 2011; 185: 281-286.

13. Mezcua M, Ferrer I, Hernando MD, Fernandez-Alba AR. Photolysis and photocatalysis of bisphenol A: identification of degradation products by liquid chromatography with electrospray ionization/time-of-flight/mass spectrometry (LC/ESI/ToF/MS). Food Addit Contam 2006; 23: 1242-1251.

14. Zhan M, Yang X, Xian Q, Kong L. Photosensitized degradation of bisphenol $A$ involving reactive oxygen species in the presence of humic substances. Chemosphere 2006; 3: 378-386. 